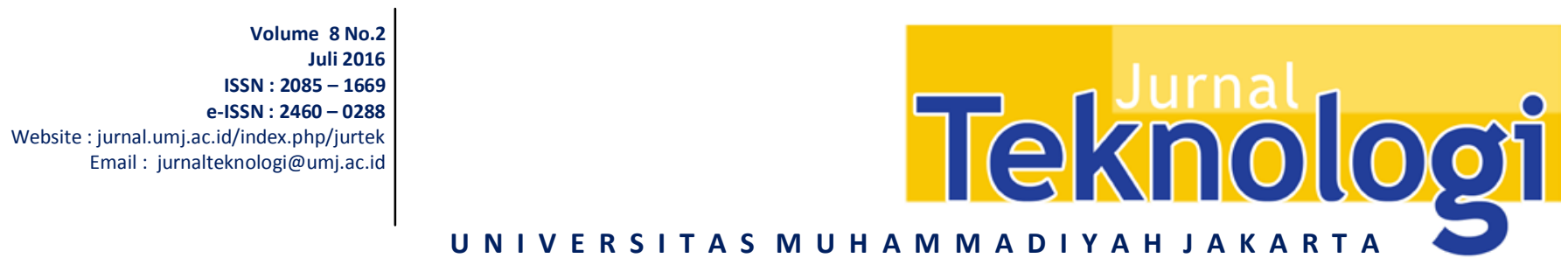

\title{
ANALISIS KELAYAKAN INDUSTRI KELAPA TERPADU
}

\author{
Tri Yuni Hendrawati ${ }^{1}$ dan Syamsudin $\mathbf{A B}^{2}$ \\ 1,2 Jurusan Teknik Kimia, Fakultas Teknik, Universitas Muhammadiyah Jakarta \\ Jl. Cempaka Putih Tengah 27 Jakarta Pusat 10510 \\ *Email : yuni.hendrawati@ftumj.ac.id
}

\begin{abstract}
ABSTRAK
Tanaman Kelapa merupakan salah satu komoditas perkebunan yang telah lama dikenal dan sangat berperan bagi kehidupan masyarakat. Beroperasinya Industri kelapa terpadu ini akan membantu perputaran ekonomi daerah dan pada gilirannya pendapatan daerah dan masyarakat petani akan ikut terangkat. Tujuan dari penelitian ini untuk melakukan analisis kelayakan industri kelapa terpadu. Metodologi yang digunakan adalah pengumpulan data primer dan sekunder ke daerah penghasil kelapa. Analisis kelayakan meliputi aspek teknis teknologis, aspek kelayakan pasar dan pemasaran, aspek finansial dan aspek dampak sosial dan lingkungan. Salah satu alternatif untuk meningkatkan nilai tambah dan efisiensi usaha perkebunan kelapa rakyat adalah dengan mengembangkan usaha pengolahan kelapa terpadu yaitu pendirian pabrik kelapa terpadu kapasitas kecil. Industri kelapa terpadu kapasitas kecil berpotensi untuk dikembangkan di perkebunan kelapa dengan kapsitas pengolahan 20.000 butir kelapa/hari. Berdasarkan perhitungan neraca massa pada proses produksi, maka setiap 20.000 butir kelapa/hari dapat menghasilkan dessicated coco $1.860 \mathrm{~kg} / \mathrm{hari}$, coco powder $1.172 \mathrm{~kg} / \mathrm{hari}$, minyak kelapa $632 \mathrm{~kg} / \mathrm{hari}$, coir fibre $11.250 \mathrm{~kg} / \mathrm{hari}$, briket arang $2.880 \mathrm{~kg} / \mathrm{hari}$, asap cair 2.880 liter/hari dan nata de coco 117.600 gelas/hari. Dari analisis secara teknis dapat disimpulkan bahwa pengembangan industri kelapa terpadu 20.000 butir kelapa/hari layak untuk direalisasikan. Pendirian industri kelapa terpadu kapasitas 20.000 butir/hari membutuhkan modal investasi sebesar Rp 13.435.000.000,- dengan modal kerja untuk selama 3 (tiga) bulan sebesar Rp 2.963.145.150,--. Hasil perhitungan NPV berdasarkan aliran kas bersih pada proyeksi arus kas industri kelapa terpadu Rp 3.493.291.768 ,- pada discount factor (DF) 20\% dan nilai IRR adalah 27.67\%. Sedangkan masa pengembalian modal (PBP) tercapai selama periode 3,53 tahun dengan nilai Net B/C sebesar 1,26. Dari hasil Analisa sensitivitas yang dilakukan, dihasilkan bahwa dengan penurunan harga produk sebesar 5\% dan kenaikan harga beli bahan baku 10\% tetap layak. Mengingat dalam praktiknya bunga bank 17,5\% dan perubahan harga beli bahan baku selalu berhubungan positif dengan harga jual produk, sehingga dengan hasil Analisa sensitivitas tersebut, diproyeksikan kegiatan usaha ini layak diimplementasikan.
\end{abstract}

Kata kunci: Kelayakan, Industri Kelapa Terpadu, Dessicated Coco

\section{ABSTRACT}

Plants Coconut is one of the commodities that have long been known and greatly contribute to people's lives. The operation of the integrated oil industry will help the economic turnaround area and in turn local revenue and the farming community will come up. The purpose of this study to analyze the feasibility of integrated coconut industry. The methodology used is primary and secondary data collection to oil producing regions. The feasibility analysis covering the technical aspects of 
technological, market feasibility and marketing aspects, financial aspects and aspects of social and environmental impacts. One alternative to increase the added value and efficiency of palm plantation business people is to develop an integrated coconut processing business, namely the establishment of an integrated oil mill with a small capacity. Integrated Coconut Industry smaller capacity could be developed in the palm with a processing capacity of 20,000 coconuts / day. Based on the calculation of mass balance in the production process, then every 20,000 coconuts / day can produce dessicated coco $1.860 \mathrm{~kg} /$ day, coco powder 1,172 kg / day, coconut oil $632 \mathrm{~kg} /$ day, coir fiber 11,250 kg / day, charcoal briquettes 2,880 kg / day, liquid smoke 2.880 liters / day and nata de coco 117,600 cups / day. From the technical analysis can be concluded that the development of integrated coconut industry 20,000 coconuts / day deserves to be realized. Establishment of an integrated coconut industry capacity of 20,000 eggs / day requires a capital investment of Rp 13.435 billion, - the working capital for the period of 3 (three) months amounted to $R p$ 2,963,145,150, -. The results of the NPV calculation is based on net cash flow in the cash flow projections integrated coconut industry Rp 3,493,291,768, the discount factor (DF) of $20 \%$ and the value of IRR is $27.67 \%$. Meanwhile, a payback period (PBP) is achieved over a period of 3.53 years with a Net B / C of 1.26. From the results of the sensitivity analysis performed, resulting that the decline in product prices by $5 \%$ and the increase in the purchase price of raw materials $10 \%$ remains appropriate. Given in practice bank interest of $17.5 \%$ and the change in the purchase price of raw materials is always associated positively with the selling price, so that the results of the sensitivity analysis, the projected business activities is feasible to implement.

Keywords: Feasibility, Integrated Coconut Industry, Dessicated Coco

\section{PENDAHULUAN}

Produksi buah kelapa Indonesia rata-rata 15,5 milyar butir/tahun atau setara dengan 3,02 juta ton kopra, 3,75 juta ton air, 0,75 juta ton arang tempurung, 1,8 juta ton serat sabut, dan 3,3 juta ton debu sabut (Allorerung dan Lay, APCC, 2014). Kelapa merupakan tanaman serba guna dapat dimanfaatkan dari akar sampai daunnya.

Tanaman Kelapa merupakan salah satu komoditas perkebunan yang telah lama dikenal dan sangat berperan bagi kehidupan masyarakat. Bila ditinjau dari aspek ekonomi, tanaman ini mempunyai nilai ekonomis yang tinggi, tiap bagian dari komoditas ini dapat menghasilkan berbagai produk-produk yang mempunyai nilai jual. Peluang bisnis yang dihasilkan oleh komoditas ini cukup banyak, mulai dari batang, daun, sabut, batok, air dan dagingnya semua mempunyai nilai bisnis yang cukup menjanjikan . Beberapa produk yang dapat dihasilkan dari komoditas ini yakni batang ( dimanfaatkan untuk bahan bangunan, furniture maupun untuk bahan interior), daun/ lidi (dianyam menjadi sapu, bahan dekorasi), daging ( diolah menjadi minyak, santan, kopra, dessicated coco, coco powder dll), tempurung (arang tempurung, briket arang, karbon aktif), sabut ( Fiber sheet, coco dust) dan air kelapa (Nata de coco).

Kegiatan industri kelapa terpadu akan memberi dua keuntungan sekaligus yakni pertama menguntungkan dari segi agrobisnis dan yang kedua turut menjaga kelestarian alam. Kelapa adalah komoditas perkebunan yang mempunyai luas areal terbesar yang sampai saat ini belum banyak disentuh para investor, sedangkan potensi yang ada seperti telah diuraikan diatas bila didayagunakan akan memberi keuntungan dari segi bisnis. Disamping itu, bagi pemerintah daerah dan masyarakat akan merupakan sumber penghasilan tambahan. Beroperasinya proyek ini akan membantu perputaran ekonomi daerah dan pada gilirannya pendapatan daerah dan masyarakat petani akan ikut terangkat. Salah satu faktor yang dapat dijadikan acuan keberhasilan kegiatan ini adalah ketersediaan bahan baku. Jumlah bahan baku harus memenuhi tiga aspek yakni kuantitas, kualitas dan kontinuitas. Untuk itu dalam pengembangan agroindustri kelapa terpadu diperlukan suatu analisa perencanaan strategi yang matang sehingga diperoleh hasil yang optimum dari setiap penggunaan sumber daya. Analisa perencanaan strategi penting dilakukan 
karena setiap saat terjadi perubahan, persaingan yang semakin ketat, peningkatan inflasi, penurunan tingkat pertumbuhan ekonomi, perubahan teknologi yang semakin canggih, dan perubahan kondisi demografis, yang mengakibatkan berubahnya selera konsumen secara cepat. Persaingan ketat yang terjadi dalam lingkungan perdagangan internasional kelapa menuntut kemampuan untuk mengembangkan keunggulan bersaing yang dimiliki.

Studi kelayakan (feasibility study) meliputi area kelayakan utama dan area kelayakan lain jika diperlukan, yang dikenal sebagai TELOS (Technical, Economic, Legal, Operational and Scheduling). Secara garis besar, studi kelayakan dikaji melalui multi aspek, antara lain aspek teknis teknologis, aspek pasar dan pemasaran, aspek finansial, dan aspek dampak sosial dan lingkungan. Yang kemudian dikembangkan/break down menjadi lebih spesifik, utamanya dari aspek teknis yang mencakup berbagai hal seperti bahan baku, infrastruktur, teknologi, tenaga kerja, utilitas, lokasi dan lain sebagainya. Selain itu, terdapat aspek-aspek tambahan seperti aspek sosial dan aspek lingkungan, juga dapat dipertimbangkan dalam studi kelayakan.

\section{METODE}

Metodologi yang digunakan adalah pengumpulan data primer dan sekunder ke daerah penghasil Kelapa (diantaranya Banten dan Jawa Barat). Analisis kelayakan meliputi aspek teknis teknologis, aspek keekonomian, aspek pasar dan pemasaran, aspek manajemen kualitas dan aspek Sosial budaya. Data kelayakan diambil dari data literatur dan dari industri kelapa terpadu sejenis.

\section{HASIL DAN PEMBAHASAN}

\section{Kelayakan Aspek Teknis Teknologis}

Industri kelapa terpadu yang prospektif dikembangkan meliputi Dessicated Coco, Coco Powder, Minyak kelapa, Nata de coco, Coir fibre dan briket arang, asap cair. Produk yang dirancang pada agroindustri kelapa terpadu meliputi Dessicated Coco, Coco powder dan coco oil dengan produk samping coir fiber, briket arang, asap cair dan nata de coco. Data rencana pengembangan dapat dilihat pada Tabel berikut.
Tabel 1. Data rencana pengembangan Industri Kelapa Terpadu

\begin{tabular}{|c|c|c|c|c|c|c|}
\hline $\begin{array}{l}\text { Potensi } \\
\text { bahan } \\
\text { baku } \\
\text { (ton/th) }\end{array}$ & $\begin{array}{l}\text { Produk } \\
\text { olahan }\end{array}$ & $\begin{array}{c}\text { Kapasitas } \\
\text { bahan } \\
\text { baku } \\
\text { (ton/bulan) }\end{array}$ & $\begin{array}{c}\text { Kapasitas } \\
\text { produksi } \\
\text { (ton/bulan) }\end{array}$ & $\begin{array}{c}\text { Rendemenen } \\
\text { (Yield) }\end{array}$ & Potensi pasar & $\begin{array}{l}\text { Harga } \\
\text { produk }\end{array}$ \\
\hline $\begin{array}{c}\text { Sabut } \\
\text { kelapa, } \\
604(25 \%)\end{array}$ & Coir fibre & $50(100 \%)$ & 37.5 & $75 \%$ & $\begin{array}{c}6,3 \\
\text { Mton/bulan } \\
\text { (1\% pasar } \\
\text { dunia) USD } \\
0.4 \text { jt (2005) }\end{array}$ & $\begin{array}{l}\text { USD } \\
182 \mathrm{MT}\end{array}$ \\
\hline $\begin{array}{c}\text { Batok } \\
\text { kelapa } 386 \\
(16 \%)\end{array}$ & $\begin{array}{c}\text { - Briket } \\
\text { arang } \\
\text {-Asap cair }\end{array}$ & $\begin{array}{l}24(75 \%) \\
8(25 \%)\end{array}$ & $\begin{array}{c}8 \\
2,7\end{array}$ & $\begin{array}{l}30 \% \\
30 \%\end{array}$ & & $\begin{array}{l}\text { Rp 6000,- } \\
\text { 15.000,- } \\
\text { /liter }\end{array}$ \\
\hline $\begin{array}{c}\begin{array}{c}\text { Daging } \\
\text { kelapa }\end{array} \\
\text { (31\%) }\end{array}$ & $\begin{array}{l}\text { - Dessicated } \\
\text { coco } \\
\text { - Coco } \\
\text { powder } \\
\text { - Coco oil }\end{array}$ & $\begin{array}{c}31(50 \%) \\
19(30 \%) \\
12.5(20 \%)\end{array}$ & $\begin{array}{l}6,2 \\
3,8 \\
2,1\end{array}$ & \begin{tabular}{l|}
$20 \%$ \\
$20 \%$ \\
$17 \%$ \\
\end{tabular} & $\begin{array}{c}200-300 \\
\text { ton bln } \\
168 \text { ton bln } \\
\\
288 \text { ton bln }\end{array}$ & $\begin{array}{c}\text { USD } \\
887 / \mathrm{MT} \\
\mathrm{Rp} \\
31.500 \mathrm{~kg} \\
\text { Rp } 5600 / \mathrm{kg} \\
\end{array}$ \\
\hline $\begin{array}{l}\text { Air kelapa } \\
676(28 \%)\end{array}$ & $\begin{array}{c}\text { Nata de } \\
\text { coco }\end{array}$ & $56(100 \%)$ & 56 & $100 \%$ & $72 \operatorname{ton} / b \ln$ & Rp 1500/kg \\
\hline
\end{tabular}

Teknologi proses industri kelapa terpadu ini dirancang untuk dapat mengolah 20.000 butir/hari dengan pembagian 50\% untuk produk dessicated coco, 30\% coco powder dan $20 \%$ coco oil. Produk samping berupa nata de coco, coco fiber, briket arang dan asap cair.

Adapun neraca massa perencanaan pengolahan kelapa terpadu dapat dilihat pada Gambar 1.

Mesin dan peralatan utama yang dipakai dalam proses produksi kelapa terpadu adalah mesin pengupasan sabut, mesin pembelahan buah, mesin pencungkilan kelapa, mesin pemarutan, mesin pengeringan pada dessicated coco, mesin penyaring santan, pemisah (decanter pada coco powder), mesin pemanas pada pengolahan minyak kelapa. Peralatan lain yang digunakan adalah peralatan pemindahan bahan, peralatan laboratorium, pengujian kualitas dan peralatan K3 dan tangan seperti sarung tangan, penutup telinga, sepatu boot, helm dan sekop. 


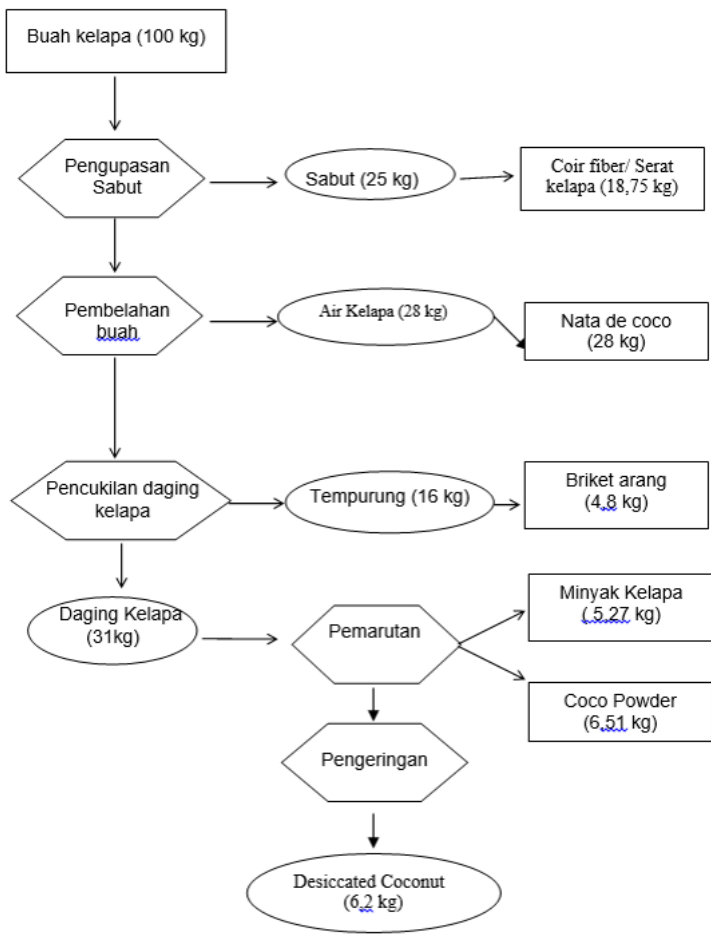

Gambar 1. Neraca Massa Pengolahan Kelapa Terpadu

\section{Ketersediaan Bahan Baku}

Pada penelitian ini agroindustri kelapa terpadu ini kapasitas ditentukan yaitu sebesar 20.000 butir buah kelapa /hari sehingga diharapkan dapat dijadikan referensi daerah yang akan membangun.

\section{Kebutuhan Utilitas}

Utilitas yang dibutuhkan untuk mengolah kelapa menjadi produk turunannya antara lain adalah air dan listrik. Sedangkan dalam operasionalnya pemenuhan kapasitas produksi industri kelapa terpadu dilakukan secara bertahap. Pada tahun ke - 1 berproduksi pada tingkat 50\%, tahun ke-2 diproyeksikan naik menjadi $75 \%$ dan pada tahun ke-3 sampai seterusnya akan beroperasi secara penuh $(100 \%)$.

\section{Jaminan Peralatan, Spare Parts dan Unjuk Kerja Alat}

Jaminan diberikan 1 tahun sejak tanggal penyerahan dari kesalahan fabrikasi tetapi tidak berlaku jika kerusakan disebabkan karena kesalahan dalam pemakaian peralatan dan operasi. Peralatan yang dibeli dari vendor, jaminan langsung diberikan oleh vendor sedangkan untuk peralatan yang di fabrikasi sendiri, dijamin ketersediaan suku cadangnya dipasaran atau suplai jika memerlukan penggantian.

\section{Spare Parts}

Menyediakan ketersediaan spare part bagi peralatan yang harus diganti secara berkala untuk keperluan operasi 3600 jam.

\section{Unjuk Kerja Alat}

Unjuk kerja alat dijamin sesuai spesifikasi.

\section{Kelayakan Aspek Kelayakan Pasar dan Pemasaran}

Sebutan desiccated coconut adalah produk kelapa parut kering. Srilanka adalah Negara pertama yang mengembangkan produk kelapa parut kering. Kemudian disusul oleh Filipina, Malaysia dan Indonesia. Dan saat ini Filipina merupakan Negara penghasil kelapa parut kering terbesar di dunia. Pada tahun 1990 Filipina mampu mengekspor produk ini sebanyak 75.341 MT, sedangkan Srilanka hanya hanya 52.673 MT. Ekspor kedua Negara ini mampu memenuhi permintaan pasar sebanyak 60-65\%. Indonesia sendiri hanya mampu memasok 1,98\% dari total permintaan dunia yang mencapai 139.516 MT. Asian and Pacific Coconut Community (APCC) memperkirakan bahwa permintaan dunia terhadap kelapa parut kering akan terus meningkat seiring dengan penggunaannya yang makin luas untuk berbagai produk makanan dan lainnya.

Pelaku usaha di Indonesia belum secara optimal memanfaatkan peluang pasar yang dijanjikan produk ini. Sementara banyak permintaan dari Amerika, Singapura dan Hongkong yang belum terlayani. Salah satu produsen kelapa parut kering di Indonesia (Unicotin) mampu mengekspor 200 - 300 ton per bulan. Namun demikian, ekspor ini belum memenuhi kapasitas permintaan negara pengimpornya yang mencapai 500 ton/bulan. Adanya permintaan pasar terhadap produk ini menunjukkan indikasi cukup cerahnya peluang pasar di masa mendatang dan Indonesia memiliki potensi untuk merebut peluang pasar yang ada.

Dewasa ini banyak dijumpai di pasar lokal maupun luar santan kelapa dalam bentuk produk kering (Coco Instan) maupun cairan/pasta yang diawetkan dan dikemas dalam plastik, kaleng atau tetrapack. Masyarakatpun lebih menyukai kepraktisan yang ditawarkan santan olahan ini. Masyarakat yang membutuhkan santan tidak perlu lagi membeli kelapa dan membuat santan sendiri tapi cukup datang ke supermarket untuk 
mendapatkan santan yang siap digunakan. Oleh karenanya, industri santan olahan (Coco Milk/Powder) memiliki prospek yang cukup bagus untuk dikembangkan dengan mempertimbangkan faktor kebutuhan dan kepraktisan yang ditawarkan.

Peningkatan permintaan juga disertai dengan naiknya harga minyak kelapa di pasar dunia. Menurut data CocoInfo International, volume 12, No.2, 2005, harga minyak kelapa di pasar intemasional cenderung naik melebihi harga minyak kelapa sawit. Harga minyak kelapa bulan Desember tahun 2005 mencapai US \$ 533 per ton. Sedangkan harga minyak kelapa sawit malah sebaliknya turun menjadi US \$ 429 per ton dari US \$ 443 pada bulan sebelumnya (Nopember 2005). Kondisi seperti ini merupakan tantangan yang harus dimanfaatkan oleh produsen kelapa di Indonesia untuk menembus pasar intemasional. Seiring dengan perkembangan penggunaan serat sabut kelapa, nilai ekspor dan harga serat sabut kelapapun meningkat. Meningkatnya harga serat sabut kelapa di pasar internasional disebabkan oleh meningkatnya permintaan negara Eropa dan Amerika terhadap produk serat sabut kelapa tersebut. China, Amerika dan Eropa merupakan pangsa pasar terbesar bagi perdagangan serat sabut kelapa. Pada tahun 2005 tercatat nilai impor dunia terhadap produk coir fibre mencapai sekitar USD 25 juta dengan negara pengimpor utama antara lain : China (USD 9.5 juta), Jerman (USD 3.5 juta dan AS (USD 2.8 juta). Sedangkan ekspor dunia untuk produk coconut fibre mencapai sekitar USD 100 jt dengan negara pengekspor utama adalah China (USD 5,4 juta), Jerman (USD 1 juta), AS (USD 0,7 juta) dan Perancis (USD 0,6 Juta). Indonesia menempati peringkat ke 7 dengan total nilai ekspor USD 0,4 juta.

Potensi pasar untuk briket arang tempurung masih terbuka lebar karena permintaan selama ini dari 1 perusahaan saja yaitu 50.000 ton / tahun baru dapat dipenuhi 18.000 ton / tahun khusus untuk pasar Eropa saja. Dari kapasitas 1,5 ton briket arang / hari yang direncanakan maka dalam 1 tahun hanya menghasilkan 450 - 500 ton briket arang / tahun yang masih jauh dari kekurangan permintaan ekspor. Harga produk final (nilai kalor > 7.000 Kkal / kg) yang diperkirakan Rp 2.000,- / kg marginnya masih cukup lebar dibanding dengan harga ekspor ke Eropa yang saat ini berkisar antara 0,60 USD / kg - FOB dan harga dalam negeri (Dept Store) yang saat ini harganya mencapai Rp 9.550,- / kg. Perbandingan harga lain untuk briket arang tempurung dengan nilai kalor sekitar 5.000 Kkal / kg untuk tujuan ekspor ke Korea harganya 0,40 USD / kg sampai di Korea atau sekitar 0,37 USD / kg - FOB.

\section{Kelayakan Aspek Finansial Asumsi-Asumsi Dasar}

Dalam penyusunan analisa keuangan, digunakan beberapa asumsi-asumsi dasar yang mengacu pada hasil-hasil perhitungan yang telah dilakukan pada aspek-aspek yang lain, standar pembangunan pabrik dan peraturanperaturan pemerintah yang berkenaan dengan hal itu. Asumsi-asumsi dasar yang dipakai dalam pengkajian pendirian agroindustri kelapa terpadu kapasitas 20.000 butir kelapa/hari ini adalah :

1. Umur ekonomis proyek adalah 11 tahun, dimana 1 tahun merupakan masa persiapan lahan dan konstruksi serta 10 tahun adalah periode produksi/operasi sesuai dengan umur ekonomis mesin dan peralatan.

2. Kapasitas produksi adalah sebagai berikut Kebutuhan bahan baku 20.000 butir kelapa/hari, Jam operasi 8 jam per hari. Hari operasi 25 hari/bulan atau 300 hari/tahun

3. Produksi akhir $1.860 \mathrm{~kg}$ dessicated coco/hari, $172 \mathrm{~kg}$ coco powder/hari, 17.600 gelas nata de cocoSumber dan struktur permodalan berasal dari modal sendiri $100 \%$.

4. Tingkat suku bunga bank per tahun diasumsikan adalah 20\% untuk kredit Investasi dan $20 \%$ untuk kredit modal kerja.

5. Perhitungan finansial dilakukan dalam mata uang rupiah dengan nilai tukar (exchange rate) 1 US\$ = Rp. 9500,-

6. Harga bahan baku dan produksi akhir didasarkan pada harga bulan Oktober 2006 dan harga produk $40 \%$ dari harga pasar adalah sebagai berikut :

a. Harga bahan baku Kelapa adalah Rp.700,-/butir 

b. Harga Dessicated Coco adalah Rp.8.000,-/kg
c. Harga jual minyak kelapa adalah Rp. $4000,-/ \mathrm{kg}$
d. Harga jual Coco powder adalah Rp. $10.000,-/ \mathrm{kg}$
e. Harga jual Nata de coco adalah Rp.400,-/gelas
f. Harga jual coir fiber adalah Rp.250,- $/ \mathrm{kg}$
g. Harga jual briket arang adalah Rp.700,-/kg
h. Harga asap cair adalah Rp.750,-/kg

7. Pabrik mulai beroperasi pada tahun ke-1 dengan kapasitas 50\%, tahun ke-2 beroperasi 75\% dan tahun ke-3 sampai ke10 pabrik beroperasi penuh $(100 \%)$ dan tahun ke - 0 digunakan untuk masa persiapan dan konstruksi.

8. Biaya penyusutan dihitung dengan metode garis lurus (straight-line method) yang disesuaikan dengan umur ekonomis masing-masing modal tetap.

9. Biaya perbaikan dan perawatan modal tetap dengan kisaran 2,5 - 5\% pertahun dari nilai investasi barang.

10. Pajak Penghasilan (PPh) dihitung berdasarkan SK. Menteri Keuangan RI No. 598/KMK.04/1994 pasal 21 tentang Pajak Pendapatan Badan Usaha dan Perseroan, sehingga besarnya pajak yang harus dibayarkan sebagai berikut : apabila pendapatan mengalami kerugian maka tidak dikenakan pajak, apabila pendapatan per tahun kurang dari Rp. 25.000.000,maka dikenakan pajak sebesar 10 persen, selanjutnya bila pendapatan berada antara Rp. 25.000.000,- sampai Rp. 50.000.000,maka dikenakan pajak 10 persen dari Rp. 25.000.000,- ditambah dengan 15 persen dari pendapatan yang telah dikurangi dengan Rp. 25.000.000,-, maka ditetapkan pajak 10 persen dari Rp. 25.000.000,ditambah 15 persen dari Rp.25.000.000,dan ditambah lagi 30 persen dari pendapatan yang telah dikurangi dengan Rp. 50.000.000,-.

\section{Perkiraan Modal Proyek}

Modal proyek yang dimaksud dibagi dalam dua bagian, yaitu modal investasi dan modal kerja. Modal investasi adalah semua modal yang diperlukan dari tahap pra operasi sampai pabrik siap beroperasi atau berproduksi. Modal kerja adalah modal yang diperlukan agar pabrik dapat berjalan dan memproduksi barang sebagaimana mestinya.

\section{Modal Investasi}

Pembangunan agroindustri kelapa terpadu membutuhkan modal investasi sebesar $\mathrm{Rp}$ 13.435.000.000,- dengan komposisi biaya seperti dalam Lampiran 1. Modal investasi ini meliputi biaya penyiapan tanah dan studi amdal, pengerjaan bangunan sipil, pengadaan alat dan mesin, peralatan kantor dan laboratorium, biaya pra operasi yang meliputi kegiatan engineering, pembuatan struktur, pengiriman barang, erection, commisioning dan uji coba serta pengawasan.

\section{Modal Kerja}

Modal kerja dapat dikelompokan dalam dua bagian, yaitu biaya tetap (fix cost) dan biaya tidak tetap (variable cost). Komponen biaya tetap meliputi gaji/upah bagi tenaga manajemen (tenaga kerja yang tidak terlibat langsung dalam proses produksi), penyusutan barang, biaya kantor untuk administrasi dan biaya perbaikan alat dan mesin produksi. Pembelian bahan baku berupa kelapa, biaya pengemas, biaya pengolahan, biaya bahan bakar dan gaji/upah untuk tenaga kerja langsung staf produksi dan tenaga kerja non staff produksi merupakan biaya variabel pengolahan kelapa.

Perhitungan modal kerja dibuat berdasarkan asumsi kebutuhan pengeluaran selama 3 (tiga) bulan produksi. Total modal kerja yang diperlukan untuk kebutuhan produksi 3 (tiga) bulan pada produksi sebesar $50 \%$ dari kapasitas terpasang adalah Rp 2.963.145.150,-.

\section{Sumber dan Struktur Pembiayaan}

Sumber pembiayaan untuk pembangunan agroindustri kelapa terpadu untuk modal tetap modal sendiri 100\%. Analisa Kelayakan Investasi

Kriteria kelayakan yang dipakai meliputi NPV, PBP, Net B/C dan IRR yang dapat menggambarkan apakah proyek masih atraktif untuk direalisasikan. Hasil perhitungan selengkapnya terhadap semua komponen kriteria kelayakan disajikan dalam Lampiran 11. Hasil perhitungan NPV berdasarkan aliran kas bersih pada proyeksi arus kas industri kelapa terpadu dengan discount factor (DF) 20\%, menghasilkan jumlah Rp 3.493.291.768,Nilai IRR untuk industri kelapa terpadu 20.000 butir kelapa/hari adalah $27.67 \%$, lebih besar 
dibandingkan dengan tingkat suku bunga yang ditetapkan yaitu 20\%. Bunga pinjaman pada bank saat ini adalah $17,5 \%$.

Masa pengembalian modal (PBP) industri kelapa terpadu 20.000 butir kelapa/hari adalah tercapai selama periode 3,53 tahun. Nilai Net B/C yang diperoleh dari pendirian industri kelapa terpadu ini adalah 1,26. Tabel 15 memperlihatkan rekapitulasi kriteria kelayakan investasi industri kelapa terpadu 20.000 butir/hari.

Tabel 15. Kriteria Kelayakan Investasi Industri Kelapa Terpadu

\begin{tabular}{|l|c|c|}
\hline $\begin{array}{c}\text { Kriteria } \\
\text { Investasi }\end{array}$ & Satuan & Nilai \\
\hline NPV & Rp. & 3.493 .291 .768 \\
\hline IRR & $\%$ & 27.67 \\
\hline Net B/C & - & 1,26 \\
\hline PBP & Tahun & 3,53 \\
\hline
\end{tabular}

Dari hasil perhitungan kriteria kelayakan proyek yang dilakukan terhadap rencana pendirian industri kelapa terpadu 20.000 butir/hari, maka kegiatan usaha tersebut secara finansial layak untuk direalisasikan dalam kondisi sesuai dengan asumsi yang dipakai karena semua nilai-nilai perhitungan telah memenuhi kriteria kelayakan suatu proyek.

\section{Analisa Sensitivitas Investasi}

Sebagai upaya untuk mengantisipasi berbagai kemungkinan seperti gejolak/fluktuasi harga, baik harga jual produk atau harga beli bahan baku, maka dilakukan analisa sensitivitas. Sensitivitas investasi diukur terhadap perubahan nilai IRR, NPV, B/C Ratio dan PBP. Analisa sensitivitas dilakukan untuk melihat apakah proyek masih layak jika terjadi kesalahan atau perubahanperubahan dalam asumsi dasar yang digunakan. Analisa sensitivitas pada industri kelapa terpadu 20.000 butir/hari dengan DER 100:0 dilakukan terhadap perkiraan penurunan harga jual produk sebesar $5 \%$ dan kenaikan harga bahan baku kelapa sebesar 10\%.

Tabel 16. Analisa Sensitivitas Investasi Industri Kelapa Terpadu

\begin{tabular}{|r|l|c|c|c|c|}
\hline & \multicolumn{1}{|c|}{ Perubahan Kondisi } & $\begin{array}{c}\text { NPV } \\
\text { (DF 20\%) }\end{array}$ & $\begin{array}{c}\text { IRR } \\
\%\end{array}$ & $\begin{array}{c}\text { Payback } \\
\text { Period } \\
\text { (th) }\end{array}$ & $\begin{array}{c}\text { Net } \\
\text { B/C }\end{array}$ \\
\hline 1. & Normal & 3.493 .291 .768 & 27.67 & 3.53 & 1,26 \\
\hline 2. & Bahan baku naik 10\% & 2.610 .754 .162 & 25.81 & 3.71 & 1.19 \\
\hline 3. & $\begin{array}{l}\text { Harga jual produk turun } \\
\text { 5\% }\end{array}$ & 905.786 .854 & 22,07 & 4.13 & 1,07 \\
\hline
\end{tabular}

Dari hasil analisa sensitivitas tersebut, tampak bahwa dengan penurunan harga jual Produk sebesar 5\% dengan asumsi harga bahan baku kelapa tetap maka terjadi penurunan IRR menjadi sebesar $22.07 \%$ dan tingkat pengembalian modal sampai dengan 4,13 tahun. Terhadap kenaikan harga bahan baku sampai $10 \%$ dengan asumsi harga jual produk tetap maka terjadi penurunan IRR menjadi sebesar 25,81 \% dan Payback Periode 3,71 tahun. Perlu disampaikan bahwa dalam prakteknya, suku bunga pinjaman $17,5 \%$ sehingga dengan asumsi discount rate 20\% pada nilai IRR pada 22,07 \% masih layak. Perubahan harga beli bahan baku selalu berhubungan positif dengan harga jual produk, sehingga dengan hasil analisa sensitivitas tersebut, dapat dinyatakan kegiatan usaha ini layak untuk diimplementasikan.

\section{Kelayakan Aspek Dampak Sosial dan Lingkungan}

Dampak lingkungan yang mungkin terjadi pada saat pembangunan dan beroperasinya industri kelapa terpadu ini antara lain : kerusakan jalan, adanya penurunan kualitas udara, kepunahan vegetasi dilokasi rencana pembangunan industri kelapa terpadu, kebisingan dan gangguan terhadap kehidupan biota air sungai. Untuk menghindari dan menanggulangi masalah - masalah tersebut maka dilakukan suatu usaha pengelolaan dan pemantauan lingkungan. Usaha pengelolaan tersebut antara lain dengan : membatasi beban dan kecepatan kendaraan yang melalui jalan disekitar pembangunan industri kelapa terpadu, pemasangan cerobong asap, penanaman kembali vegetasi di sekitar industri kelapa terpadu dan membuat serta mengoperasikan IPAL. Sedangkan usaha untuk pemantauan lingkungan yang dilakukan antara lain : mengukur kualitas udara ambient sekitar industri kelapa terpadu, emisi gas buang, tingkat kebauan, tingkat kebisingan, baku mutu air limbah dan lain - lain.

Selain dampak lingkungan, akan muncul pula dampak sosial dari adanya pembangunan industri kelapa terpadu baik positif maupun dampak negatif. Dampak sosial negatif yang dapat muncul antara lain : keresahan penduduk selama pembangunan industri kelapa terpadu dan adanya kecemburuan sosial tenaga kerja lokal, sedangkan dampak sosial positif yang mungkin akan muncul adalah : adanya jaminan 
pemasaran kelapa bagi perkebunan rakyat disekitar industri kelapa terpadu dan terciptanya peluang berusaha bagi jasa angkutan kelapa. Untuk menanggulangi keresahan penduduk dan kecemburuan sosial tenaga kerja lokal maka perlu dilakukan suatu usaha pengelolaan dan pemantauan terhadap dampak sosial yang timbul. Usaha yang dilakukan antara lain: melakukan pendekatan sosial dan menjalin hubungan dengan penduduk setempat, menganjurkan karyawan pendatang agar dapat bergaul dengan masyarakat sekitar, memberikan kesempatan kepada masyarakat sekitar industri kelapa terpadu menjadi tenaga kerja, memberikan kesempatan kerja kepada pengusaha lokal untuk menjadi rekanan industri kelapa terpadu dan lain - lain.

\section{KESIMPULAN DAN SARAN \\ Kesimpulan}

Dari hasil penelitian ini dapat disimpulkan

sebagai berikut:

1. Pertumbuhan luas lahan dan volume produksi kelapa rakyat belum diimbangi dengan peningkatan daya saing, nilai tambah dan efisiensi usaha. Salah satu alternatif untuk meningkatkan nilai tambah dan efisiensi usaha perkebunan kelapa rakyat adalah dengan mengembangkan usaha pengolahan kelapa terpadu yaitu pendirian pabrik kelapa terpadu kapasitas kecil. Industri kelapa terpadu kapasitas kecil berpotensi untuk dikembangkan di perkebunan kelapa dengan kapsitas pengolahan 20.000 butir kelapa/hari.

2. Suatu komoditas industri yang menyangkut hidup rakyat banyak bila hanya dikuasai oleh pemain skala besar sangat rawan terhadap pembentukan harga baik bahan baku (kelapa) maupun harga produk yang mengarah pada kartel dan pasar yang oligopoli. Oleh karena itu membangun dan membina pengusaha UKM yang berkeinginan bergerak di industri kelapa terpadu kapasitas kecil namun sehat dan efisien sangat perlu didukung oleh semua pihak.

3. Dalam konteks tersebut merencanakan akan membangun industri kelapa terpadu berkapasitas 20.000 butir kelapa/hari dengan harapan semua pihak yang terkait dapat kiranya memberikan dukungan agar rencana ini dapat terwujud serta berhasil dalam operasionalnya.

4. Proses produksi pada industri kelapa terpadu kapasitas 20.000 butir kelapa/hari ini meliputi produksi dessicated coco, coco powder, minyak kelapa, coir fibre, asap cair dan nata de coco. Mesin dan peralatan yang digunakan merupakan mesin dan peralatan yang dibuat sesuai dengan kebutuhan dengan standar alat yang ada di Pasar sehingga ada jaminan spare part.

5. Berdasarkan perhitungan neraca massa pada proses produksi, maka setiap 20.000 butir kelapa/hari dapat menghasilkan dessicated coco $1.860 \mathrm{~kg} / \mathrm{hari}$, сосо powder $1.172 \mathrm{~kg} / \mathrm{hari}$, minyak kelapa 632 $\mathrm{kg} / \mathrm{hari}$, coir fibre $11.250 \mathrm{~kg} / \mathrm{hari}$, briket arang $2.880 \mathrm{~kg} / \mathrm{hari}$, asap cair 2.880 liter/hari dan nata de coco 117.600 gelas/hari. Dari analisis secara teknis dapat disimpulkan bahwa pengembangan industri kelapa terpadu 20.000 butir kelapa/hari layak untuk direalisasikan.

6. Rencana Pembangunan industri kelapa terpadu 20.000 butir kelapa/hari akan dikelola oleh Badan Pengelola yang dipimpin oleh seorang direktur. Direktur dibantu oleh 3 orang manajer yaitu manajer bagian administrasi/keuangan, proses produksi dan pengendalian mutu. Kebutuhan total tenaga kerja adalah 34 orang terdiri dari 4 orang karyawan staf dan 30 orang karyawan non staff.

7. Pendirian industri kelapa terpadu kapasitas 20.000 butir/hari membutuhkan modal investasi sebesar Rp 13.435.000.000,dengan modal kerja untuk selama 3 (tiga) bulan sebesar Rp 2.963.145.150,--. Hasil perhitungan NPV berdasarkan aliran kas bersih pada proyeksi arus kas industri kelapa terpadu Rp 3.493.291.768 ,- pada discount factor (DF) $20 \%$ dan nilai IRR adalah 27.67\%. Sedangkan masa pengembalian modal (PBP) tercapai selama periode 3,53 tahun dengan nilai Net B/C sebesar 1,26.

8. Dari hasil Analisa sensitivitas yang dilakukan, dihasilkan bahwa dengan penurunan harga produk sebesar 5\% dan kenaikan harga beli bahan baku 10\% tetap layak. Mengingat dalam praktiknya bunga bank 17,5\% dan perubahan harga beli bahan baku selalu berhubungan positif dengan harga jual produk, sehingga 
dengan hasil Analisa sensitivitas tersebut, diproyeksikan kegiatan usaha ini layak diimplementasikan.

\section{Saran}

Dari hasil penelitian ini merupakan acuan dalam pendirian Industri Kelapa Terpadu dan jika akan dibangun perlu dilakukan Analisa kelayakan detail dan penentuan lokasi yang tepat. Untuk pembangunan masih diperlukan Detailed Engineering Design.

\section{UCAPAN TERIMAKASIH}

Terima Kasih kepada LPPM, Universitas Muhammadiyah Jakarta atas pembiayaan penelitian ini sesuai dengan Surat Perjanjian Pelaksanaan Program Penelitian Internal Tahun Anggaran 2015 Nomor 364/R$\mathrm{UMJ} / \mathrm{X} / 2015$.

\section{DAFTAR PUSTAKA}

Agustian, A., S. Friyatno, Supadi dan A. Askin. 2003. Analisa pengembangan agroindustry komoditas perkebunan rakyat (kopi dan kelapa) dalam mendukung peningkatan daya saing sektor pertanian. Makalah Seminar Hasil Penelitian Pusat Penelitian dan Pengembangan Sosial Ekonomi Pertanian Bogor. T.A. 2003. 38 hal

Allorerung, D., dan A. Lay. 1998.

Kemungkinan pengembangan

pengolahan buah kelapa secara terpadu skala pedesaan. Prosiding Konperensi Nasional Kelapa IV. Bandar Lampung 21 - 23 April 1998 Pp.327 340.

APCC. 2003. Coconut statistical yearbook 2002, Asia Pacipic Coconut Community.

Anonymous. 2004. Teknologi Tanaman Industri : Kelapa (Cocos nucifera). http://www.kelapa.html (22 juli 2004).

Brown, H. J., Copeland, L. R., Kleiman R., Cummings, M. K., Koritala, S., Manoramarao, K. High Unsaponifiables and Methods of Using The Same. 2011. United States Patent Application Pubblication: US2011/0293544 A1.

Desnelli dan Zainal Fanani, 2007. Kinetika Reaksi Oksidasi Asam Miristat, Stearat dan Oleat dalam

Medium
Minyak Kelapa, Minyak Kelapa Sawit serta Tanpa Medium

Departemen Kesehatan Republik Indonesia. 1985. Formularium Kosmetika Indonesia : Jakarta.

Departemen Kesehatan Republik Indonesia. 1989. Farmakope Indonesia III : Jakarta.

Esti, Sawedi. 2001. Tanaman Perkebunan. Jurnal Pengolahan Pangan Dewan Ilmu Pengetahuan. Teknologi dan Industri Sumatera Barat.

Estiasih, Teti dan Ahmadi. 2009. Teknologi Pengolahan Pangan. Bumi Aksara: Malang. $\quad$ Firmansyah.2011. Studi Operasi Pengeringan pada Proses Pembuatan Kopi Instan dengan Menggunakan Pengering Tipe Semprot. Skripsi Jurusan Keteknikan Pertanian Fakultas Teknologi Pertanian Universitas Brawijaya. Malang

Janur Bisma Tama, dkk. 2014 .Studi

Pembuatan Bubuk Pewarna Alami dari Daun Suji (Pleomele Angustifolia N.E.BR.).Kajian Konsentrasi Maltodekstrin dan MGCO3. Jurnal Perindustrian Vol 3 No 1 Hal 73 - 82 Fakultas Teknologi Pertanian Universitas Brawijaya, Malang

Julie, 2011.Palmitic Acid and Skin. http://www.prosperorganics.com/2011/0 9/palmitic-acid- and-skin/ Desember 2014)

Lahmudin, Agus. 2006. Proses Pembuatan Tepung Putih Telur dengan Pengering Semprot. Laporan Skripsi Program Studi Teknologi Hasil Ternak Fakultas Peternakan Institut Pertanian Bogor.

Larosa, Yedid Novrianus. 2007. Studi Pengetsaan Bentonit Terpilar $\mathrm{Fe}_{2} \mathrm{O}_{3}$. Skripsi Departemen Kimia

Unieversitas Sumatera Utara. Medan.

Larose Kumalla M, Sumardi H.S, dan M. Bagus Hermanto.2013. Uji Performasi Pengering Semprot Tipe Buchi B-290 Pada Proses Pembuatan Tepung Santan.Jurnal Bioproses Komoditas

Tropis.Jurusan Keteknikan Pertanian Fakultas Teknologi Pertanian Universitas Brawijaya. Malang.

Lieberman, Lachman . 1994. Teori dan Praktek Farmasi Industri Jilid 2. UI press : Jakarta. 
Nur, I.I, Kardiyono, Umar, dan Aris A. 2003. Pemanfaatan limbah debu sabut kelapa dalam usaha tani padi pasang surut.Kelembagaan Perkelapaan di Era Otanomi Daerah, Prosiding Konferensi Nasional Kelapa V. Tembilahan 22-24 Oktober 2002.

Riahna br Kembaren, Sesotya Putriliniar, Nurwenda Novan Maulana, Radyum Ikono, Nurul Taufiqu Rochman. 2013. Ekstraksi dan Karakterisasi Serbuk Nano Pigmen dari Daun Tanaman Jati (Tectona grandis linn. F). Prosiding Semirata FMIPA Universitas Lampung.

Rindengan, B., A. Lay., H. Novarianto., H. Kembuan dan Z. Mahmud. 1995. Karakterisasi daging buah kelapa hibrida untuk bahan baku industri makanan. Laporan Hasil Penelitian.Kerjasama Proyek Pembinaan Kembagaan Penelitian Pertanian Nasional. Badan Litbang 49p.

Roberto C.G., Werner, M., Manfred K. 1996. Drying characteristic of copra and quality of copra and coconut oil. Journal Posharvest Biology and Technologi 9: 361-372.

Soedjoko T.S., 1987, "Penelitian Pemanfaatan Bentonit di Indonesia”,Buletin PPTM Vol. 9, No. 2, Jakarta, Hal. 15-24. Srinivasan, D and Alain, P. 1997. Food Proteins and Their Applications. New York: Marcel Dekker Inc

Tarwiyah, Kemal. 2001. Tepung Aren. Jurnal Pengolahan Pangan Dewan Ilmu Pengetahuan, Teknologi dan Industri Sumatera Barat.

Waide, Ainley, and Waller, Paul J. 1994. Handbook of Pharmaseutical Exipients. 6th edition. Washington American Pharmaseutical Association. Winarno, F.G. 1997. Kimia Pangan dan Gizi. Gramedia. Jakarta 